\title{
COMBINED TRACE ELEMENT, SM-ND, LU-HF- AND RE-OS STUDIES CONSTRAIN THE AGE, ORIGIN AND THE DEVELOPMENT OF THE KAAPVAAL SUBCRATONIC MANTLE
}

\author{
Brey $^{*} \mathbf{G P}^{1}$, Luchs $\mathbf{T}^{\mathbf{1}}$, Shu $\mathbf{Q}^{\mathbf{1}}$, Lazarov $\mathbf{M}^{\mathbf{1}, 2}$, Becker $^{3}{ }^{3}$ \\ ${ }^{1}$ Frankfurt University, Germany; ${ }^{2}$ TU Hannover; ${ }^{3}$ Freie Universitaet Berlin, Germany; \\ brey@em.uni-frankfurt.de
}

Processes connected with the formation and modification of the sub-continental lithospheric mantle are recorded in the trace element abundances and isotope ratios of peridotites and their constituent minerals. The main hosts for lithophile elements are garnet and clinopyroxene in grtlherzolites. Their analysis will yield uncontaminated bulk rock information on the nature of partial melting and enrichment processes. We analysed single crystal subcalcic garnets, bulk rocks and срx and grt separates from grtharzburgites and -lherzolites from Bellsbank, Finsch, Roberts Victor and Bultfontein diamond mines in South Africa (Archean on-craton) and from grt-lherzolites from the Gibeon province in Namibia (mostly proterozoic crust; off-craton) (Fig. 1).

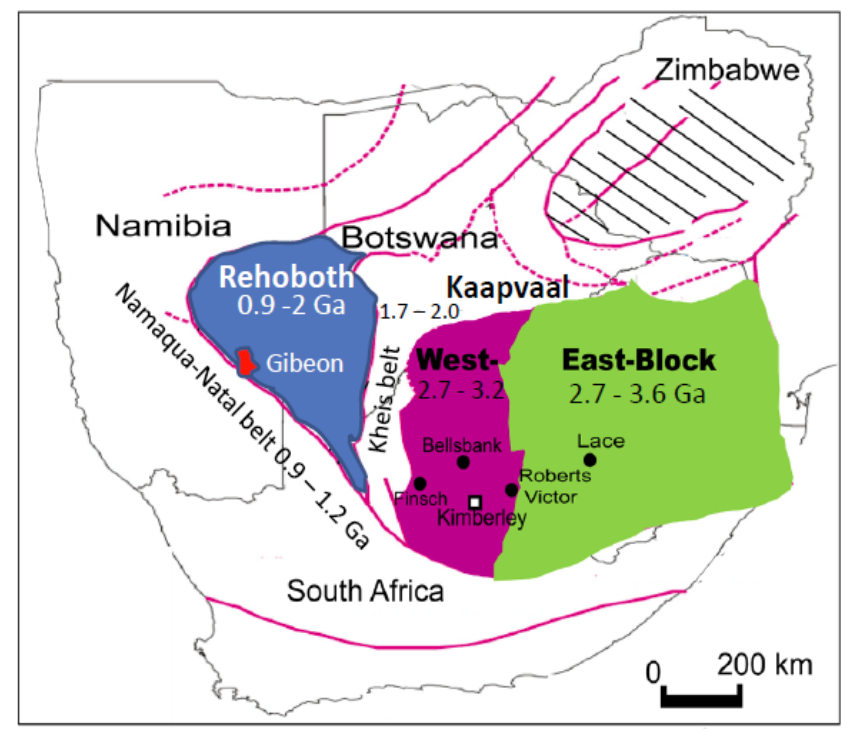

Fig. 1 Localities investigated, major crustal building blocks of southern Africa and their ages

A summary of Bell et al. (2003) shows that the conductive geothermal gradients beneath the Gibeon
Province and the Kaapvaal craton coincide, that it finishes at shallower depth in Gibeon and that there is a distinct departure of high temperature peridotites in both mantle areas from the main array. This occurs at shallower depths in Gibeon than on the Kaapvaal craton (Fig. 2).

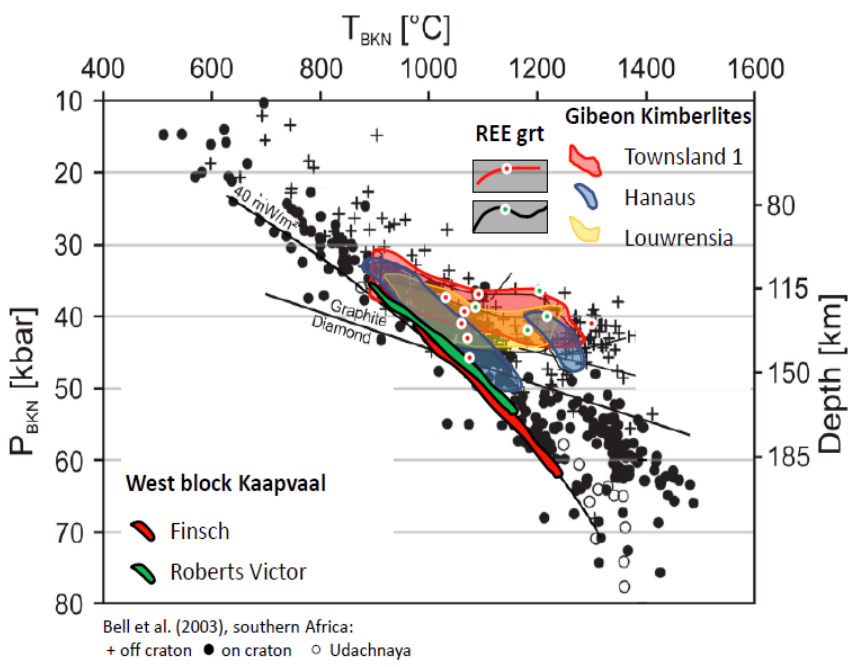

Fig. 2: The thermal structure of the lithospheric mantle underneath Gibeon and the Kaapvaal Craton after a compilation of mantle xenoliths P/T conditions by Bell et al. (2003).

All peridotites are residues of partial melting which were metasomatically overprinted to various extents. Elements like $\mathrm{Cr}$, the HREE and possibly Hf may be exempt from reenrichment and still record the partial melting event(s). On-craton samples mostly show sigmoidal REE patterns in their garnets which are also seen in about $30 \%$ of the garnets from the off-craton peridotites from Gibeon. About $70 \%$ of the Gibeon garnets, however, have LREE depleted patterns typical for mantle samples from Proterozoic crustal sections. The extent of reenrichment or preservation of the residual composition can be visualized e.g. in a diagram of chondrite normalized $\mathrm{Lu} / \mathrm{Hf}$ against 
Lu/Er (Fig. 3) where samples plotting into quadrant I have experienced the least or no metasomatic overprint whereas all others are strongly disturbed. We therefore analysed only quadrant I samples for their Sm-Nd and Lu-Hf isotopic composition in an attempt to derive the timing of partial melting and reenrichment. In addition bulk rock samples from Finsch were analysed for Re-Os and the Re-Os data avaible from the literature reevaluated.

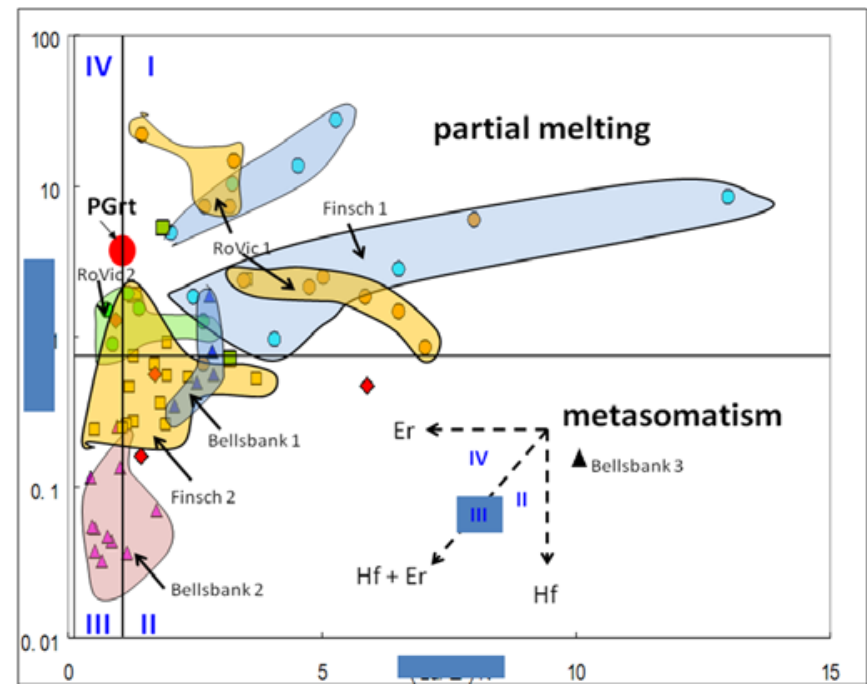

Fig. 3: . $\log (\mathrm{Lu} / \mathrm{Hf})_{\mathrm{N}}-(\mathrm{Lu} / \mathrm{Er})_{\mathrm{N}}$ variation diagram for sub-calcic garnets. PGrt denotes a garnet composition from a primitive peridotite from Vitim. Only those garnets are used for further isotope work which plot into quadrant $I$ which is the field into residue of partial melting should fall.

No reliable iochrones were obtained for the Sm-Nd system because multiple enrichment events changed the $\mathrm{Sm}-\mathrm{Nd}$ ratios in an unsystematic fashion. From Finsch, LuHf isochrons of $2.64 \mathrm{Ga}$ and $2.62 \mathrm{Ga}$ are derived from subcalcic garnets and calculated bulk rocks (= the modal amounts of grt and cpx) respectively; initial $\varepsilon \mathrm{Hf}$ values are +23and +16 (Fig. 4a). Our Re-Os systematics derived from the bulk rocks yield an errorchron of $2.35 \pm 1.1 \mathrm{Ga}$ in support of the Lu-Hf ages. The isochrones have to be interpreted as dating an enrichment event which is supported by our Re-Os data and those of Griffin et al. (2004) on sulphides in Finsch xenoliths (Fig. 4b). Corresponding ages in the crust appear with the onset of the voluminous Ventersdorp volcanism.

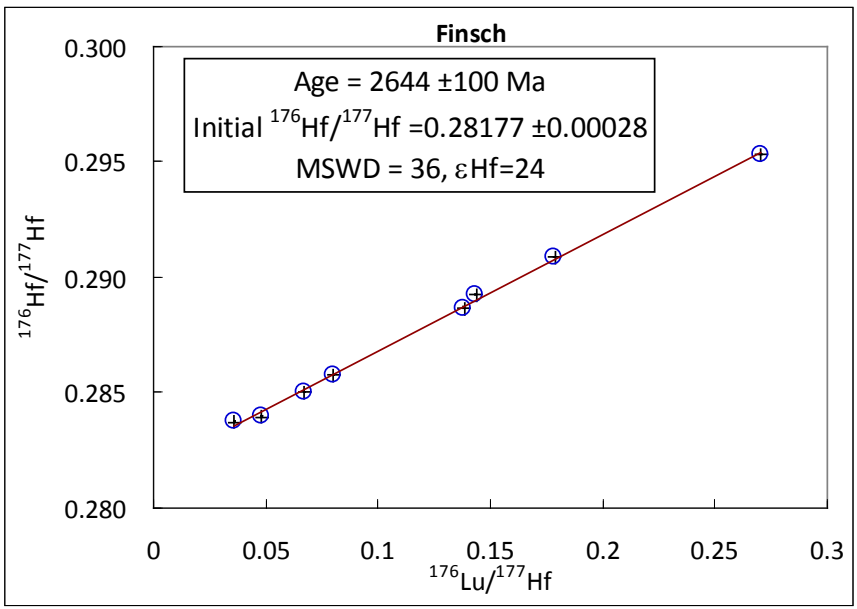

Fig. 4a: Lu/Hf isochron of subcalcic garnets from Finsch. It is interpreted as dating an enrichment event which may reflect the onset of the processes occurring in the mantle in connection with the eruption of the voluminous Ventersdorp lavas.

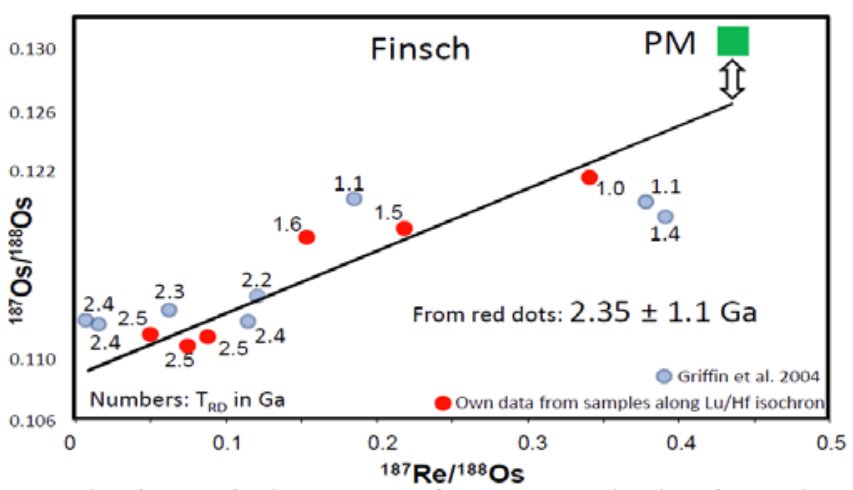

Fig. 4b: Re-Os isotope data from bulk peridotites from Finsch with a Lu-Hf enrichment age of $2.62 \mathrm{Ga}$ (red dots). Light blue dots are Re-Os data on single sulfides from Finsch xenoliths by Griffin et a. (2004). The data indicate an enrichment event with an age consistent with our Lu-Hf data. Numbers are Rhenium depletion ages.

The subcalcic garnets from Roberts Victor yield two isochrones (Fig. 4), one at $2.95 \mathrm{Ga}$ with $\varepsilon \mathrm{Hf}=0$ and a second with $3.27 \mathrm{Ga}$ and $\varepsilon \mathrm{Hf}=17$. From trace element considerations, the first is interpreted as dating a partial melting event of a primitive mantle and the second as an enrichment event. The samples from Lace on the E-block scatter around the Roberts Victor 3.3 Ga isochron (Fig. 5). 


\section{$10^{\text {th }}$ International Kimberlite Conference, Bangalore - 2012}

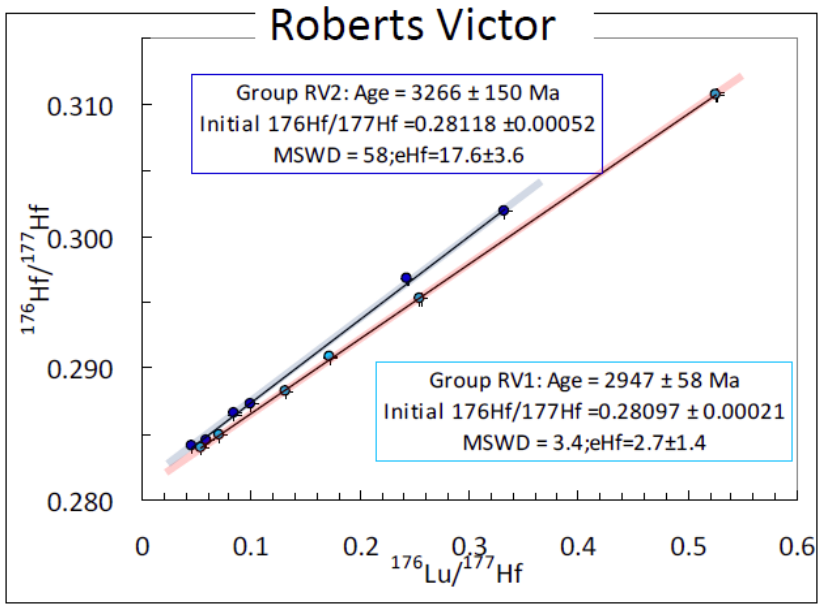

Fig. 5a: Two isochrones can be derived from Roberts Victor subcalcic garnets - one dating a partial melting event at $2.95 \mathrm{Ga}$ of a primitive mantle, a second dating an enrichment event at $3.3 \mathrm{Ga}$ of an already depleted mantle part.

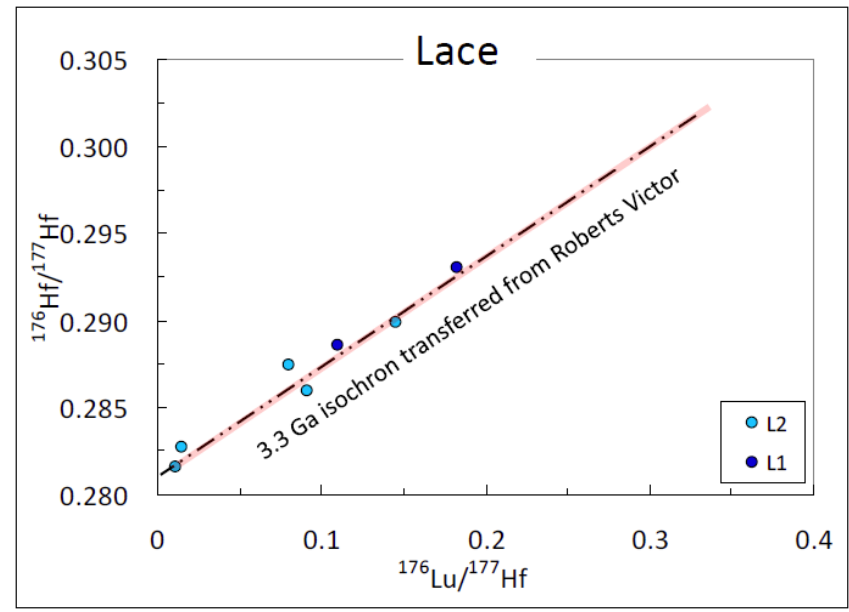

Fig. 5b: Subcalcic garnets do not yield a very defined correlation. They do, however, plot around the enrichment isochron obtained for Roberts Victor garnets.

Three sigmoidal and five LREE depleted peridotites from Gibeon yield Lu-Hf isochrones of $1.88 \pm 0.060 \mathrm{Ga}$ and $933 \pm 48$ Ma respectively (Fig. 6a). Both isochrones are interpreted as reflecting enrichment events of a previously depleted mantle. The timing and the extent of depletion must have been very different because the former yield $\varepsilon \mathrm{H}$ $=+29$, the latter +5 . Literature data for Re-Os give $T_{R D}$ ages from $<1$ to $2.2 \mathrm{Ga}$. There is a coincidence in age of the younger Gibeon samples with an isochron of $909 \pm 25 \mathrm{Ma}$ drawn through the very high Re/Os samples of Gibeon and with a second around 1.9 Ga. A conspicuous third correlation of 6 data points yields an isochrone of $2.9 \mathrm{Ga}$ (Fig. 6b). We interpret the latter as an isochron dating a first partial melting event of parts of the mantle underneath Gibeon.

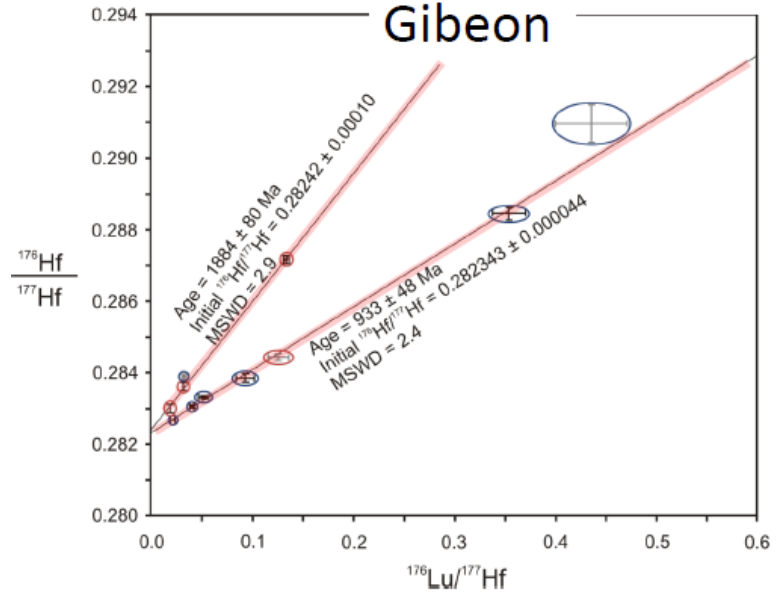

Fig. 6a:A 933 Ma enrichment isochron is obtained for calculated bulk rocks from Hanaus and Gibeon Township in the Gibeon kimberlite province in Namibia

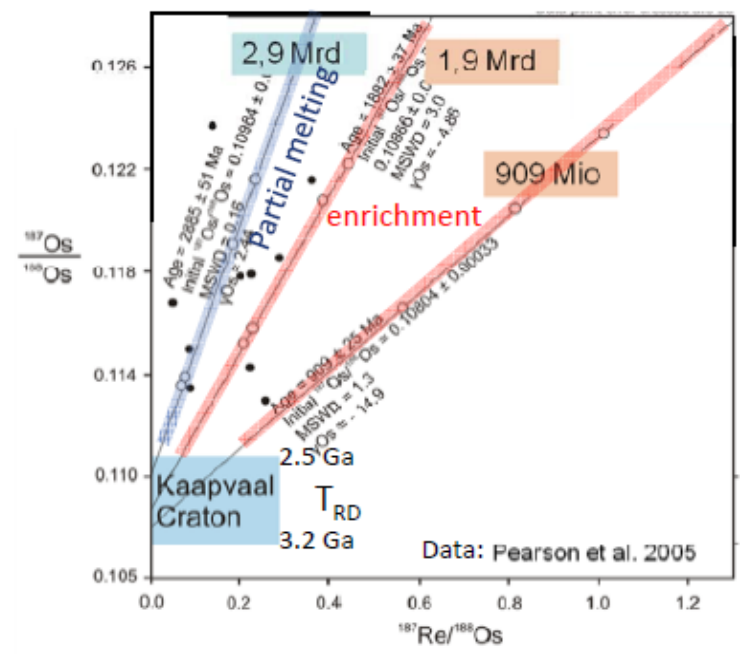

Fig. 6b: A reevaluation of the Re-Os data from Louwrensia in the Gibeon kimberlite province obtained by Pearson et al. (2005)

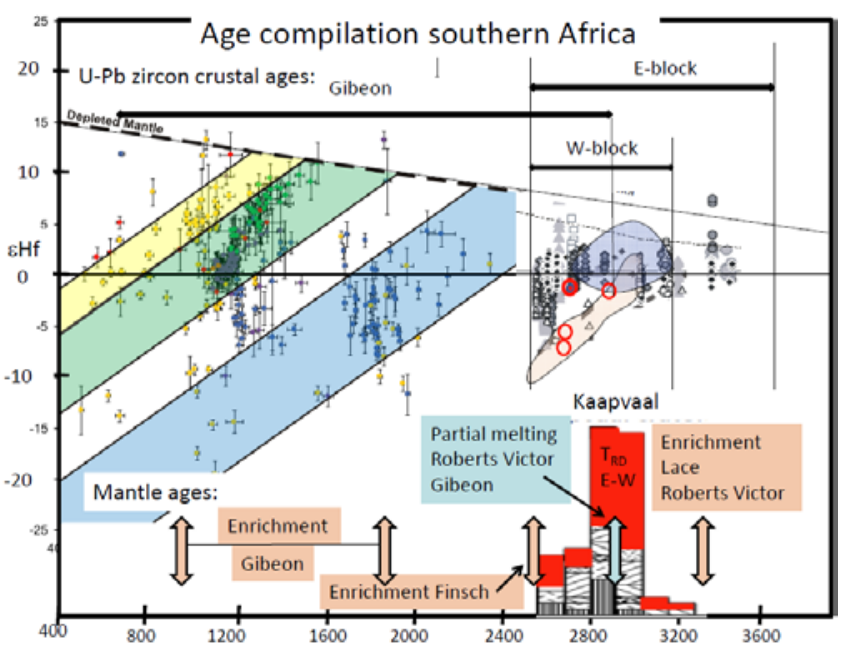

Fig. 7: Comparison of mantle with crustal ages of southern Africa 
$10^{\text {th }}$ International Kimberlite Conference, Bangalore - 2012 